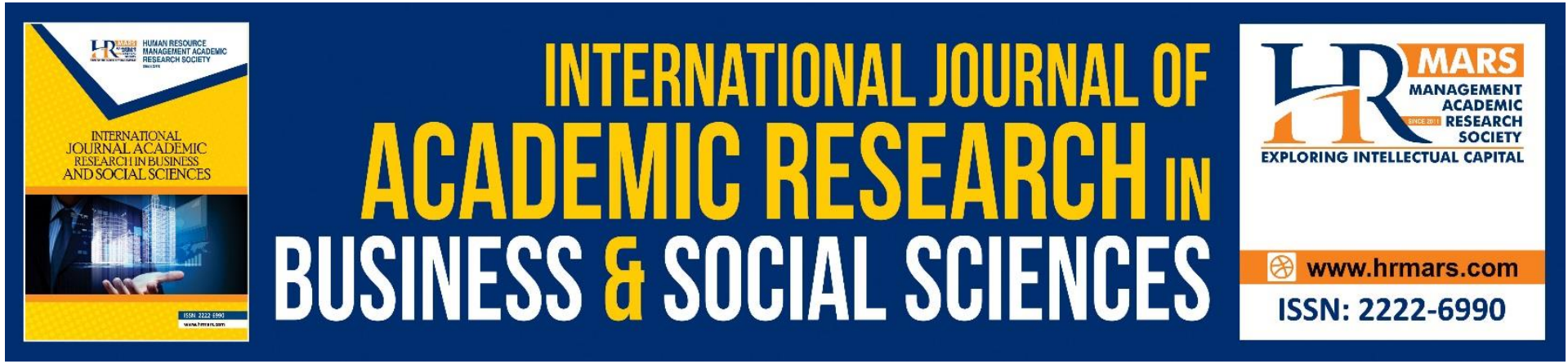

\title{
Mobile Marketing Adoption among Small and Micro Bumiputera Enterprises: a Managerial Perspective from Malaysia
}

Norzalita Abd Aziz, Wan Mohd Hirwani Wan Hussain, Fei Long

To Link this Article: http://dx.doi.org/10.6007/IJARBSS/v11-i7/10668

DOI:10.6007/IJARBSS/v11-i7/10668

Received: 22 May 2021, Revised: 25 June 2021, Accepted: 12 July 2021

Published Online: 24 July 2021

In-Text Citation: (Aziz et al., 2021)

To Cite this Article: Aziz, N. A., Hussain, W. M. H. W., \& Long, F. (2021). Mobile Marketing Adoption among Small and Micro Bumiputera Enterprises: a Managerial Perspective from Malaysia. International Journal of Academic Research in Business and Social Sciences, 11(7), 1640-1652.

Copyright: (c) 2021 The Author(s)

Published by Human Resource Management Academic Research Society (www.hrmars.com)

This article is published under the Creative Commons Attribution (CC BY 4.0) license. Anyone may reproduce, distribute, translate and create derivative works of this article (for both commercial and non-commercial purposes), subject to full attribution to the original publication and authors. The full terms of this license may be seen at: http://creativecommons.org/licences/by/4.0/legalcode

Vol. 11, No. 7, 2021, Pg. 1640 - 1652

Full Terms \& Conditions of access and use can be found at http://hrmars.com/index.php/pages/detail/publication-ethics 


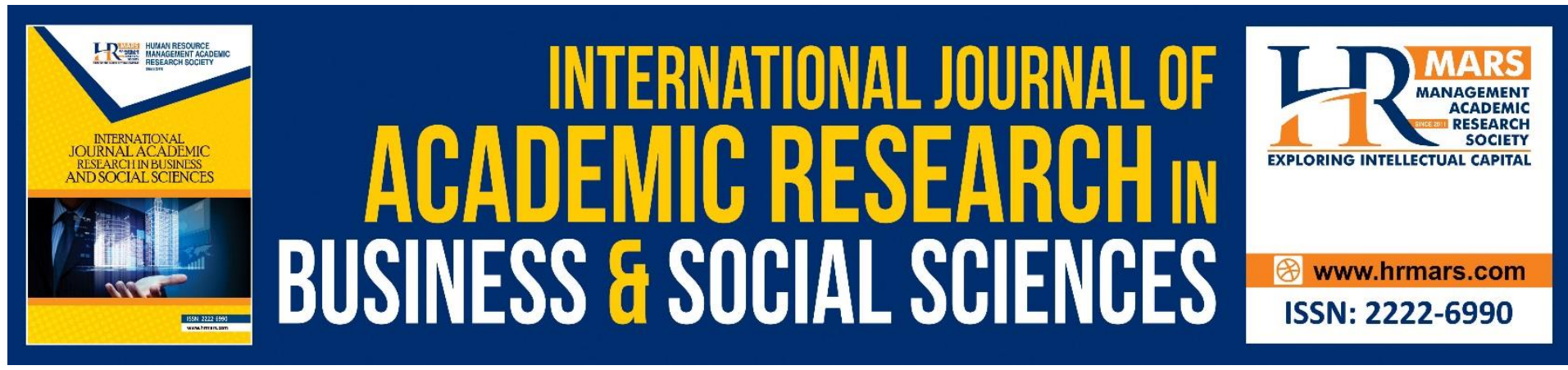

\title{
Mobile Marketing Adoption among Small and Micro Bumiputera Enterprises: a Managerial Perspective from Malaysia
}

\author{
Norzalita Abd Aziz (Associate Professor) \\ Graduate School of Business Universiti Kebangsaan Malaysia \\ Email: eita@ukm.edu.my
}

\section{Wan Mohd Hirwani Wan Hussain (Associate Professor) \\ Graduate School of Business Universiti Kebangsaan Malaysia \\ Email:wmhwh@ukm.edu.my}

\author{
Fei Long (PhD Candidate) \\ Graduate School of Business Universiti Kebangsaan Malaysia \\ Email: longfei5202005@hotmail.com
}

\begin{abstract}
Amid the current highly competitive business world, this study examined the determinant factors influencing the managerial intention to implement mobile marketing among small and micro Bumiputera enterprises in Malaysia. The study is based on the research model suggested by Okazaki and Taylor (2008). The influential variables are i) Brand Building Effect (ability to build brand image), ii) Location Based Marketing (the ability to use location-based marketing), iii) Privacy/Security Concerns (related to consumer acceptance of mobile marketing) and iv) Technological Conditions (the perceptions of the current technological infrastructure). The study also investigated the current adoption level of mobile marketing orientations among them. By analyzing data from 129 small and micro Bumiputera enterprises, it is found that location based marketing is the main factor directly influencing their managerial intention to adopt mobile marketing in Malaysia. This finding contradicts previous studies indicating that all the four factors are significantly related to managers' intention to adopt mobile marketing based on data from multinationals in Europe, Japan and the USA. The current research sheds light on the usage of mobile marketing among small and micro Bumiputera enterprises in Malaysia, which makes contributions to the relevant literature in the context of Malaysia.
\end{abstract}

Keywords: Mobile Marketing, Managerial Intention, Bumiputera, SMEs, Malaysia

\section{Introduction}

Mobile phones, especially smartphones, have become very prominent and important to everyone's daily life across the world. Almost everyone has a mobile phone in his/her pocket. 
As predicted by the Global Mobile Market Report, there are 3.5 billion smartphone users in 2020 (Newzoo, 2020). In the last few years, the penetration rate of smartphone keeps increasing in most parts of the world, including Malaysia. According to Malaysia Communication and Multimedia Commission (2019), the penetration rate of smartphone grew by $2.1 \%$ from $75.9 \%$ in 2017 to $78.0 \%$ in 2018 . Not only can mobile marketing establish a two-way communication with consumers, but also tailor ad messages based on consumers' real time geographic location. Besides, mobile marketing increases the chances that an ad message reaches the targeted consumers. It is even more crucial for small and micro enterprises for surviving and thriving as it has become an important way to communicate with consumers, make transactions and shopping (Wang et al., 2015)

The popularity of mobile marketing makes it impossible for marketers to avoid marketing activities in mobile media (Venkatesh, 2015). It is widely believed that building long term relationships and customer loyalty is extremely important for effective marketing management (Houston \& Gassenheimer, 1987). Significantly, mobile marketing helps practitioners achieve the above mentioned objectives of marketing management in different ways because it enables a two-way communication process between marketers and consumers. Many prior studies related to mobile marketing indicated that this marketing tool, as a brand building vehicle, is very effective in stimulating a customer response. Therefore, mobile marketing could improve brand attitude and consequently increase consumers' purchase intention (Rettie et al., 2005; Wang et al., 2015). In addition, mobile marketing has gradually evolved from static text messaging to dynamic and personalized notifications in the past decade (Tong et al., 2020).

Small and micro enterprises are a vital component of Malaysia's economic development and share of total exports is approximately 20 percent lower than other countries in the region such as the Philippines, Hong Kong, Taiwan (SMIDEC, 2007). They face many challenges in the current globalized environment. For example, lack of financing, low productivity, lack of managerial capabilities, poor access to management and technology (Musa et al., 2016). As reported by Bank Negara Malaysia (2008), SMEs contribute 99.2 percent to Gross Domestic Product (GDP) and provide employment for about 56 percent of the total employment in Malaysia. According to the SMIDEC Report (2007), SMEs in Malaysia remain dependent on the domestic market and are confronting more challenges of market access, advancement of technology, innovation and creativity, access to information and human development. Malaysia has adopted a common definition of SMEs to facilitate the identification of SMEs in the various sectors and subsectors.

Significantly, there is still a lack of Bumiputera (Malays and indigenous people in Malaysia) involvement in specific commercial and industrial enterprises compared to other ethnic groups. To cater to the needs of the nation's commercial and industrial development, Bumiputera's participation in commercial activities is crucial to raise the overall economic status of Malaysians. Text messages have become an important marketing communication channel for electronic and print media. Although little is known about consumers' adoption towards wireless marketing channels, many organizations are making considerable investments for the new business possibilities offered by wireless technologies. There are a large number of studies on mobile marketing, but only few discussed the perception of small 
and micro Bumiputera enterprises towards mobile marketing. Little is known about their intention to use mobile marketing.

Mobile marketing needs to receive solid support from the management of any small and micro enterprises to ensure the smooth adoption and acceptance of this marketing tool throughout the organization (Jeon et al., 2006). Musa et al (2016) indicate that SMEs' attitude and knowledge are very important criteria in mobile marketing acceptance followed by branding strategy and technical knowledge in Malaysia. In addition, marketing and managerial support is a crucial factor in technology adoption (Ahmed et al., 2019). Marketing instruments that use mobile devices (m-marketing) allow innovative forms of customer relationships and interaction and will lead to the development of numerous mobile commerce-based services (Venkatesh et al., 2003, Venkatesh, 2015).

Mobile marketing has emerged as one of the most popular applications in e-commerce. As mobile technologies are being increasingly adopted on a worldwide basis, international mobile marketing becomes an issue of growing importance. Tarhini et al., (2019) argue that more studies are needed in developing countries to gain a comprehensive understanding in mobile marketing adoption. Some studies suggest that customers focus on utilitarian values of mobile marketing (Hsu \& Yen, 2018; Tarhini et al., 2019). Nevertheless, there is insufficient research examining mobile marketing adoption and its impact on performance in a context of small and micro Bumiputera enterprises. Therefore, this study presents evidence of such firms' perceptions towards mobile marketing. The analysis is based on a survey of small and micro Bumiputera enterprises towards mobile marketing. The main purpose of this study is to examine the managerial intention to adopt mobile marketing among small and micro Bumiputera enterprises in Malaysia. Therefore, this study expects to add some values on marketing and management studies and provide some suggestions for such firms.

\section{Literature Review \\ Mobile Marketing}

Mobile marketing is considered a very significant medium that directly links customers and companies (Mobile Marketing Association, 2009). Mobile Marketing Association (2009) defines mobile marketing as "sending advertising messages to mobile devices such as mobile phones or PDAs through the wireless networks". Although the terms of wireless advertising and mobile advertising are used as synonymic terms by many authors, there are differences between the two terms in relation to what mobile devices are used for message sending and reading (such as mobile phones, PDA's, wireless networking systems, Global Positioning System locators and maps) (Salo \& Tähtinen, 2005).

According to Leppaniemi and Karjaluoto (2006), mobile marketing refers to marketing communications by using mobile medium. Companies are constantly looking for ways of expanding or maintaining their market share. Mobile devices provide opportunities for sending messages to target customers more efficiently than mass media (Tong et al., 2020; Zubcsek et al., 2017). Mobile phone has become extremely important to customers and thus marketers view mobile marketing as a critical communication channel with huge potential (Kavassalis et al., 2003, Venkatesh, 2015). 


\section{Brand Building Effect}

Based on prior research, mobile marketing has a considerable contribution towards brand building (Kumar \& Mittal, 2020). Regarding website usage, McMillan et al. (2003) argue that perceived interactivity is an influential factor determining an end user's attitudinal tendencies towards a website and it is more influential than the websites' number of features. According to Hopkins and Turner (2012), the most stunning feature of mobile technology is its ability to build brands with customers and prospects. The content of a company's brand is able to be delivered to target customers via mobile gadgets (Zhou, 2011). Mobile marketing has a high level of interactivity as it could redirect a consumer to a company's website or social media pages. In a modern business world, building brand is a fundamental goal for a company, and increasing brand equity lies at the centrality of many marketing campaigns (Tong et al., 2020). Mobile marketing could facilitate companies achieving the goal of building brand because it can easily disseminate information that could enhance potential customers' brand awareness and purchase intention (Berger \& Milkman, 2012; Chiem et al., 2010). As a result, a company is very likely to improve its business performance. Considering the potentials of mobile marketing with regard to a company's long-term brand building and business performance, managers probably will become more acceptable towards mobile marketing. Thus, we hypothesize:

H1. Firms' intention to use mobile advertising is positively associated with perceptions of mobile marketing's ability to build the brand.

\section{Location Based Marketing}

The popularity of smartphone provides a foundation of location-based services, including address finders, e-hailing and food delivery. These services have brought much convenience to consumers, so they have become an inseparable part of many consumers' daily life (Pagani, 2004; Tang \& Hew, 2017). Significantly, location-based services could make mobile marketing more effective by sending location specific messages to target consumers. Location-based messages are defined as information sent out with taking where the receivers are into account (Stafford \& Gillenson, 2003). With such an accurate message-sending mechanism, consumers' needs may be well catered with location-based offers and promotions (Tong et al., 2020). For example, a small or micro enterprise may send promotional information, such as price reduction, to consumers who stay near the company. Not only is real-time locationbased information useful for marketers, but also customers' historical location information that may indicate their product preferences (Zubcsek et al., 2017). Empowered by mobile data in relation to location, time and other social factors, mobile markers could predict consumers' behavioral patterns, which may help companies understand consumers' purchase decision making process (Tong et al., 2020). To sustain in the market, mobile marketers should obtain the ability to deliver suitable information to the right audiences through good quality systems, good communication providers and database management (Grewal et al., 2016). Given mobile marketing's ability to link location, ad message and consumers, companies are willing to participate in mobile marketing for improving their market performance (Tong et al., 2020). Thus, we hypothesize:

H2. Firms' intention to use mobile marketing is positively associated with their perception of the ability of the medium to allow them to pursue location-based marketing. 


\section{Privacy/Security Concerns}

It has been mentioned earlier that the popularity of smartphone lays a foundation for the wide application of mobile marketing. However, wireless gadgets, such as smartphone, do not ensure that consumers will definitely accept mobile marketing (Kumar \& Mittal, 2020). Mobile marketing must solve a number of public policy concerns, including consumer privacy and confidentiality before its full potential can be realized. Kavasallis et al. (2003) explain that a prerequisite of effective mobile marketing is to get permission from consumers to send them mobile messages. If consumers do not feel confident that companies will properly protect their privacy, they probably won't accept mobile marketing campaigns (Banerjee et al., 2021). In the past decade, SPAM issue, as a privacy intrusion, has become increasingly serious. Bulk emails are often sent to smartphone users, which are usually seen as a privacy violation from a consumer perspective. As a response, many consumers block, reject or delete such messages before reading them. Thus, mobile marketers have to take consumers' privacy issues into consideration to avoid invalid mobile marketing campaigns. Although personalized services associated with smartphone do provide convenience to their end-users, consumers are aware that such convenience comes at a price. Consumers have to give away some power to companies by disclosing some of their personal data. When consumers feel that their information privacy and confidentiality can not be guaranteed at a satisfactory level, they may refuse to provide requested data or give false information to companies (Banerjee et al., 2021). Consequently, privacy fears may not only be limiting the growth of mobile marketing, but may also be affecting the validity and completeness of customer databases and profiles, leading to inaccurate targeting and wasted effort. As a matter of fact, consumer's concerns over their privacy keeps reminding marketers to implement mobile marketing in a userfriendly approach with optimal content design (Tong et al., 2020). Thus, we hypothesize:

H3. Firms' intention to use mobile marketing is positively associated with perceptions of privacy and security concerns of mobile messaging.

\section{Technological Conditions}

With regard to technological adoption, it is believed that overall technological environment and technological affordances are positively related to adoption intention of a particular technology, including mobile marketing (Okazaki \& Taylor, 2008; Tang \& Hew, 2017). Specifically, a county's technological environment is a prerequisite to carry out a new technology as it determines whether there are enough users who have the right gadgets to be reached by mobile marketing messages (Okazaki \& Taylor, 2008). In the domain of education, it is found that a few factors, such as cost, time, device and awareness, are important to influence end-users' behavioral intention to adopt mobile messages for education purposes (Tang \& Hew, 2017). Therefore, a particular technology will be more widely used in countries which have appropriate technological environments and end-users can afford such technology. Thus, based on the availability of appropriate devices and technology, we hypothesize:

H4. Firms' intention to use mobile marketing is positively associated with perceptions of the sufficiency of the technological environment. 


\section{Methodology}

A structured survey questionnaire that applied both judgmental and convenience sampling was adopted for this study. The survey questionnaire adopted a six-point Likert-type scale from ' ' 1 ' to ' 6 ' (from strongly disagree to strongly agree) to examine the relationship between identified factors and intention to use mobile marketing among small and micro Bumiputera enterprises. 156 companies were selected from the Directory of MARA Entrepreneurs from Melaka and Selangor. Questionnaires were sent to potential respondents through e-mails. One week after the emails were sent, a telephone call was made to enquire about the progress of the responses. Two weeks were given for the respondents to reply to the questionnaire. After one month, 129 valid responses (82.7\%) were received through telephone calls, emails and faxes.

The measurement used was adopted based on related studies in the European market (Okazaki \& Taylor, 2008). The survey is composed of seven sections. The first part consists of 14 items that collect the demographic data of the respondents. The second part involves brand building effect questions that measure the perceptions of how using mobile marketing can improve a company's brand image, such as whether brand awareness will increase through the utilization of mobile marketing in Malaysian market. The third part of the questionnaire consists of questions with regard to location based marketing, such as whether mobile marketing allows marketers to use localized campaigns more effectively. The fourth part of the questionnaire attempts to understand the extent of a company's concern about security and privacy concerning mobile communication, such as a primary concern of consumers in mobile marketing is privacy and security control. The fifth part consists of questions related to technological conditions in Malaysia and whether Malaysia is suitable for mobile marketing, such as whether current connection speed is appropriate for marketing purposes in Malaysia. The sixth part consists of questions measuring a firm's intention to adopt mobile marketing in the Malaysia market and finally the seventh part consists of related questions concerning certain mobile usage in marketing activities.

\section{Findings}

\section{Company Profile}

Most of the small and micro Bumiputera enterprises are in the service and trading sector (80\%) with a small number from manufacturing companies (20\%). From the total of 129 respondents, $80 \%(103)$ are from the service and trading sector and 20\% (26) are from manufacturing companies. With regard to firm type, 17\% (22 companies) are partnership category, 40\% (52 companies) private limited and 43\% (55 companies) are sole proprietor category. In terms of product/services produced by the respondents, 52\% (67) of them provided various services including tailoring, repairing, trading, photocopying, managing events, clinics, and maintenance, $23 \%$ (30) of them produced finished products, $20 \%$ (26) of them produced consumer goods and only $5 \%(6)$ of them produced raw materials.

Concerning the number of employees, 65\% (84) of the surveyed firms had less than 5 employees, $25 \%$ (32) had 5-10 employees, 3\% (4) had $11-25$ employees, and $7 \%$ (9) had 26 50 employees. More than half of the respondents (79.12\%) generated average total sales of between RM50,000 to RM250,000 in 2019, only 4 companies managed to achieve annual sales of more than RM1 Million in 2019. In terms of providing formal Information Systems (IS) in their company, most respondents did not have a formal IS for their marketing activities. 
$57 \%$ (74) respondents say "NO" to the question asking whether they have formal IS and $43 \%$ (55) say "YES" that they do have formal IS in their organization. This is probably due to the fact that the majority of the companies mainly targeted the local market (74\%), China (8\%) and other Asian markets (18\%).

\section{Descriptive Statistics}

The following results show the mean value and standard deviation of brand building effect, location-based marketing, privacy/security concern and technological conditions.

Table 1: Mean and Standard Deviation of the Constructs

\begin{tabular}{|c|c|c|c|c|}
\hline No & Name of Construct & No of Items & Mean & Std. Deviation \\
\hline 1 & Brand Building Effect & 3 & 4.61 & 0.809 \\
\hline 2 & Location-based Marketing & 3 & 4.64 & 0.885 \\
\hline 3 & Privacy/Security Concerns & 3 & 4.52 & 0.830 \\
\hline 4 & Technological Conditions & 3 & 4.23 & 0.682 \\
\hline
\end{tabular}

As it is shown in Table 1, the highest mean value is location-based marketing (4.64) followed by brand Building effect (4.61). This result indicates that small and micro Bumiputera enterprises are very willing to adopt mobile marketing for their products/services. They also perceive that mobile marketing can improve the image of their products/services.

Table 2: Activities of Mobile Marketing

\begin{tabular}{|l|c|c|}
\hline \multicolumn{1}{|c|}{ Attributes } & Mean & Std. Deviation \\
\hline $\begin{array}{l}\text { Promote company's products, services and } \\
\text { capabilities }\end{array}$ & 4.54 & 0.704 \\
\hline $\begin{array}{l}\text { Provide product catalogue to customers and } \\
\text { prospects }\end{array}$ & 4.65 & 0.874 \\
\hline $\begin{array}{l}\text { Answer customer queries about product } \\
\text { availability, order status, etc }\end{array}$ & 4.54 & 0.704 \\
\hline Allow customer to place online orders & 4.77 & 0.967 \\
\hline $\begin{array}{l}\text { Enable sale people online access to } \\
\text { product/price/performance information }\end{array}$ & 4.62 & 0.827 \\
\hline $\begin{array}{l}\text { Enable sales-people online transmission of sales } \\
\text { call information }\end{array}$ & 4.54 & 0.735 \\
\hline $\begin{array}{l}\text { Enable online purchase of } \\
\text { resources/parts/components from supplier }\end{array}$ & 4.09 & 0.877 \\
\hline Provide online support to distributors/dealers. & 4.63 & 0.865 \\
\hline $\begin{array}{l}\text { Gather market related information on customers, } \\
\text { competitors, and industry. }\end{array}$ & 4.73 & 0.776 \\
\hline $\begin{array}{l}\text { Use visitor information for marketing and } \\
\text { prospecting }\end{array}$ & 4.78 & 0.712 \\
\hline $\begin{array}{l}\text { Realize better communication/coordination in } \\
\text { managing operations and team projects. }\end{array}$ & 4.67 & 0.761 \\
\hline
\end{tabular}

Since mobile marketing is important for business sustainability, most small and micro Bumiputera enterprises agree that the Internet has facilitated the marketing activities of small and micro enterprises to the local and even global market. As it is shown in Table 2, mobile marketing is mainly used for marketing information dissemination and collecting customer 
information. Only a few small and micro Bumiputera enterprises are ready to make transactions and payments online. Therefore, the function of mobile marketing/m-commerce has not yet taken place in such types of companies in Malaysia. It is important that they design their company websites with an m-commerce platform to give wider access to target customers for both marketing and online transaction purposes.

\section{Regression Analysis}

In order to measure the significance of the relationship between brand building effect, location-based marketing, privacy/security concerns, technological conditions and managerial intention to adopt mobile marketing, stepwise linear regression analysis method is utilized. The obtained result from the regression analysis is presented in Table 3 below.

Table 3: Regression Analysis Result

\begin{tabular}{llcccc}
\hline Independent & Unstd.B & Std. B & Error & T & $\begin{array}{c}\text { Sig. (P } \\
\text { value) }\end{array}$ \\
\hline Constant & 1.875 & 0.401 & & 4.674 & 0.000 \\
Brand & 0.145 & 0.094 & 0.183 & 1.552 & 0.124 \\
Location & 0.360 & 0.100 & 0.498 & 3.597 & 0.001 \\
Privacy & 0.016 & 0.079 & 0.021 & 0.207 & 0.836 \\
Technology & 0.050 & 0.094 & 0.053 & 0.528 & 0.599 \\
R=0.703 R Square=0.495 & & & & & \\
Sig.F=0.000 & & & & & \\
\hline
\end{tabular}

The regression analysis results in Table 3 show that only location based marketing meets the recommended significance value of $p<0.05$. Therefore, this attribute is significantly associated with the overall managerial intention to adopt mobile marketing. Only Hypothesis $2(\mathrm{H} 2)$ is supported, and the null hypothesis is rejected. $\mathrm{H} 1, \mathrm{H} 3$ and $\mathrm{H} 4$ are rejected. In addition, the model explains $49.5 \%$ of the variance of managerial intention to use mobile marketing. The model is significant, but the result shows that there may be other factors influencing small and micro Bumiputera enterprises' managerial intention towards mobile marketing in Malaysia.

\section{Discussion and Implications}

In the last two decades, there have been remarkable innovations with regard to mobile communications, which has radically changed the way business is conducted. For example, 4G technology in wireless networks provides a foundation for enabling new and convenient services for customers that were not possible before (Leppaniemi \& Karjaluoto 2005). Meanwhile, these technological innovations make it possible for marketers to link target customers with their real-time location for personalized services and marketing activities through GPS (Global Positioning System) or their network-based solutions. The findings indicate that location based marketing is the most important factor influencing small and micro Bumiputera enterprises' intention to adopt mobile marketing in Malaysia. Moreover, the mean value of location based marketing is the highest and it has a positive and significant impact on intention to use mobile marketing. Technological developments and creative use of geographic positioning systems may enhance and change the way to do business among small and micro Bumiputera enterprises. 
Mobile is currently a popular marketing instrument and it allows context-sensitive messages and a high level of customization, and it obviously delivers added values to the surveyed small and micro Bumiputera enterprises. Most Bumiputera enterprises are in favor of adopting mobile marketing for their marketing activities. This communication channel will become even more popular when people are more familiar with this technology, especially in the rural area of Malaysia. It also should be noted that message design is not trivial. If small and micro companies decide to send out mobile marketing and promotional information, such information should be entertaining and informative. Their managers and marketers should have forward thinking by developing creative advertisements with location based tactics, such as mobile payment apps that have features to track users' geo-location. Location based marketing is a crucial reason why small and micro enterprises want to adopt mobile marketing strategies (Kache \& Seuring, 2017).

Managers also need to ensure that their target customers are willing to share location information. Managers should encourage target customers to share data in exchange for cash rewards, discounts, loyalty points and other perceived benefits (Shieh et al., 2019). By capitalizing the mobile payment options and creative advertisements as stated earlier, small and micro Bumiputera enterprises can track customers through location related data, which will facilitate them influencing their target customers' purchase decisions. Therefore, small and micro enterprises can partner with the location based marketing firms to improve post click conversion rates for improving their competitiveness in the market. They need to develop their own mobile apps or cooperate with other well-established apps (e.g. mobile payment) to alert users when new content is uploaded, which helps users or potential customers find the firm or store with proper marketing messages. Managers should develop an effective reward plan that is able to highlight the value and benefits of its services, highlight the related options of services and products and attract customers online and offline by linking customers, merchants and platform vendors.

\section{Conclusions and Limitations}

Mobile marketing is becoming increasingly personalized, so it is necessary to require a certain amount of information from message receivers. Mobile users can be reached quickly based on their physical location at a given time. Mobile marketing may provide valuable services to consumers, but it may become an intrusive practice if it does not get mobile users' prior consent. Specifically, the application of mobile communication technologies tends to collect personal information beyond necessity, which may violate individuals' privacy. Thus, there remain some open issues with regard to mobile marketing implementation, such as level and type of consent required before collecting of personal data and sending unsolicited $\mathrm{m}$ advertising.

Based on this study, we can conclude that mobile marketing does have a positive impact on small and micro Bumiputera enterprises in Malaysia. However, it presents some fundamental challenges to the current legal framework, especially concerning customer privacy protection against the violation of personal data. Consumers' personal data must be guaranteed. If their concerns about privacy are not properly addressed, the growth of mobile marketing may slow down due to lack of consumer trust. In order to provide meaningful consent prior to receiving $\mathrm{m}$-advertising, mobile users need to obtain appropriate and effective disclosure regarding the processing of personal data through mobile technologies. Consumers should be given some 
form of control over their personal data and what types of m-advertising messages they are willing to receive. The success of mobile marketing is dependent on the development and execution of legislative and industrial initiatives. Under an appropriate legislative mechanism (e.g. privacy law), industries will be pushed to develop privacy-enhancing solutions.

In general, small and micro Bupimutra enterprises have been actively involved in mobile marketing to gain competitive advantage for consumers and sales growth. However, they need government agencies' help if they tend to go global with their products. In addition, they need to take further steps in the same direction with further assistance from the government. Most small and micro enterprises agree that brand building, location-based, privacy and technological conditions and the use of the Internet are crucial in their marketing activities. They recognize that the current mobile technology has played a significant role in their marketing activities though their readiness for e-commerce is still considered relatively moderate. Despite the presence of internal and external barriers, mobile marketing will become a very common phenomenon for small and micro Bumiputera enterprises in the current market situation. Consequently, Malaysian government, through the Ministry of International Trade and Industry (MITI) and Malaysia External Trade Development Corporation (MATRADE), need to ensure that SMEs in both the manufacturing and services sectors continue to contribute significantly to the realization of the long-term competitiveness of the country.

With regard to theoretical contributions, this research advanced our understanding of why small and micro Bupimutra enterprises intend to engage in mobile marketing in Malaysia. It is found that the research model proposed by Okazaki and Taylor (2008) needs to be modified in an emerging market context. Only one (i.e. location-based marketing) of the four identified factors is influential concerning intention to use mobile marketing among small and micro Bupimutra enterprises though they think all the four factors are important. The inconsistency may suggest that mobile marketing is relatively immature in an emerging market compared to an developed one, such as Europe. Therefore, Malaysian government and other governments of emerging markets need to pay more attention to related initiatives to promote mobile marketing so as to improve their small and micro enterprises' overall competitiveness. Specifically, they should make sure that there is a favorable business and technological environment by nurturing brand building and new technology adoption awareness among small and micro enterprises. Meanwhile, emerging markets ought to update their laws and regulations to protect data privacy for the sake of companies and consumers.

This study has several limitations. Firstly, the research should be regarded as an exploratory study because it develops preliminary propositions based on managerial insights. In addition, the conceptual model only includes four antecedents predicting managerial intention to adopt mobile marketing. Thus, future research should examine some other factors, such as managerial perception of cost efficiency or expected sales-generating capacity of mobile marketing. Besides, future studies may conduct qualitative in-depth interviews with managers as the first step for identifying specific reasons to use mobile marketing to better serve the research purpose. Secondly, the sample size in the study is modest and the data were only collected from two states of Malaysia, so generalizability of this research's findings should be interpreted with caution. Thirdly, future research may collect data from more than 
one country and other regions of the world for comparison. Finally, future studies may also include the non-Bumiputera enterprises in Malaysia, which would provide valuable insights as well.

\section{References}

Ahmed, S. Z., Abu Bakar, A. R., \& Ahmad, N. (2019). Social media adoption and its impact on firm performance: The case of the UAE. International Journal of Entrepreneurial Behaviour \& Research, 25(1), 84-111.

Banerjee, S., Xu, S., \& Johnson, S. D. (2021). How does location based marketing affect mobile retail revenues? The complex interplay of delivery tactic, interface mobility and user privacy. Journal of Business Research, 130, 398-404.

Bank Negara Malaysia (2008). Small and Medium Enterprise (SME) Annual Report 2007. https://www.bnm.gov.my/-/small-and-medium-enterprise-sme-annual-report-2007

Berger, J., \& Milkman, K.L. (2012). What makes online content viral? Journal of Marketing Research, 49(2), 192-205

Chiem, R., Ariola, J., Browers, D., Gross, J., Limman, E., Nguyen, P. V., Sembodo, D. Song, Y., Seal, K. C. (2010). The critical success factors for marketing with downloadable applications: Lessons learned from selected European countries. International Journal of Mobile Marketing, 5(2), 43-56.

Grewal, D., Bart, Y., Spann, M., \& Zubcsek, P. P. (2016). Mobile advertising: a framework and research agenda. Journal of Interactive Marketing, 34, 3-14.

Hopkins, J., \& Turner, J. (2012). Go mobile: Location based marketing, apps, mobile optimised ad campaign 2D codes and other mobile strategies to grow your business. Hobokan: Wiley.

Houston, F. S., \& Gassenheimer, J. B. (1987). Marketing and exchange. Journal of marketing, 51(4), 3-18.

Hsu, C. W., \& Yen, C. C. (2018) Understanding the critical factors for successful M Commerce adoption. International Journal of Mobile Communications, 16(1), 50-62.

Jeon, B. N., Han, K. S., \& Lee, M. J. (2006). Determining factors for the adoption of e-business. The case of SMEs in Korea. Applied Economics, 38(16), 1905-1916

Kache, F., \& Seuring. S. (2017). Challenges and opportunities of digital information at the intersection of big data analytics and supply chain management. International Journal of Operations \& Production Management, 37(1), 10-36.

Kavassalis, P., Spyropoulou, N., Drossos, D., Mitrokostas, E., Gikas, G., \& Hatzistamatiou, A. (2003). Mobile permission marketing: Framing the market inquiry. International Journal of Electronic Commerce, 8(1), 55-79.

Kumar, V., \& Mittal, S. (2020). Mobile marketing campaigns: practices, challenges and opportunities. International Journal of Business Innovation and Research, 21(4), 523539.

Leppaniemi, M., \& Karjaluoto, H. (2005). Factors influencing consumers' willingness to accept mobile advertising: a conceptual model. International Journal of Mobile Communications, 3(3), 197-213.

Malaysian Communications and Multimedia Commission (MCMC). (2019). Hand Phone Users Survey 2018.

https://www.mcmc.gov.my/skmmgovmy/media/General/pdf/HPUS2018.pdf

McMillan, S. J., Hwang, J. S., \& Lee, G. (2003). Effects of structural and perceptual factors on attitudes toward the website. Journal of advertising research, 43(4), 400-409. 
Mobile Marketing Association (2009). MMA Updates Definition of Mobile Marketing. http://mmaglobal.com/news/mma-updates-definition-mobile-marketing

Musa, H., Li, S. C. H., Abas, J. A., \& Mohamamed, N. (2016). Adoption factor of mobile marketing: The case of small medium enterprises in Malaysia. International Review of Management \& Marketing, 6(S7), 112-115.

Newzoo. (2020). Newzoo Global Mobile Market Report 2020 Free Version. https://newzoo.com/insights/trend-reports/newzoo-global-mobile-market-report2020-free-version/

Okazaki, S., \& Taylor, C.R. (2008). What is SMS advertising and why do multinationals adopt it? Answers from an empirical study in European markets. Journal of Business Research, 61, 4-12.

Pagani, M. (2004). Determinants of adoption of third generation mobile multimedia services. Journal of Interactive Market, 18(3), 46-59.

Rettie, R., Grandcolas, U., \& Deakins, B. (2005). Text message advertising: Response rates and branding effects. Journal of targeting, measurement and analysis for marketing, 13(4), 304-312.

Salo, J., \& Tähtinen, J. (2005). Retailer use of permission-based mobile advertising. In Advances in electronic marketing (pp. 139-156). IGI Global.

Shieh, C-H., Xu, Y., \& Ling, I-L. (2019). How location-based advertising elicits in store purchase. Journal of Services Marketing, 33(4), 380-395.

SMIDEC (2007). Policies, Incentives, Programmes and Financial Assistance for SMEs. https://smecorp.gov.my/images/Publication/handbook/smehandbook.pdf

Stafford, T. F., \& Gillenson, M. L. (2003). Mobile commerce: what it is and what it could be. Communications of the ACM, 46(12), 33-34.

Tang, Y., \& Hew, K. F. (2017). Is mobile instant messaging (MIM) useful in education? Examining its technological, pedagogical, and social affordances. Educational Research Review, 21, 85-104.

Tarhini, A., Alalwan, A. A., Shammout, A. B., \& Al-Badi, A. (2019). An analysis of the factors affecting mobile commerce adoption in developing countries. Review of International Business and Strategy, 29(2), 157-179.

Tong, S., Luo, X., \& Xu, B. (2020). Personalized mobile marketing strategies. Journal of the Academy of Marketing Science, 48(1), 64-78.

Venkatesh, R. (2003). User acceptance of information technology: Toward a unified view. MIS Quarterly, 27, 425-478.

Venkatesh, R. (2015). Mobile marketing. International Journal of Research, 2(2), 1175-1187.

Wang, R. J. H., Malthouse, E. C., \& Krishnamurthi, L. (2015). On the go: How mobile shopping affects customer purchase behaviour. Journal of Retailing, 91(2), 217-234.

Zhou, T. (2011). Examining the critical success factors of mobile website adoption. Online Information Review, 35(4), 636-652.

Zubcsek, P. P., Katona, Z., \& Sarvary, M. (2017). Predicting Mobile advertising response using consumer colocation networks. Journal of Marketing, 81(4), 109-126. 